\title{
Evidence for loss of synaptic AMPA receptors in anterior piriform cortex of aged mice
}

\author{
James Gocel and John Larson* \\ Psychiatric Institute (M/C 912), Department of Psychiatry, College of Medicine, University of Illinois at Chicago, Chicago, IL, USA
}

\section{Edited by:}

Orly Lazarov, The University of Illinois

at Chicago, USA

\section{Reviewed by:}

Eric Blalock, University of Kentucky, USA

Junming Wang, University of

Mississippi Medical Center, USA

*Correspondence:

John Larson, Psychiatric Institute (M/C 912), Department of Psychiatry, College of Medicine, University of Illinois at Chicago, 1601 West Taylor Street, Chicago, IL 60612, USA e-mail: jrlarson@uic.edu
It has been suggested that age-related impairments in learning and memory may be due to age-related deficits in long-term potentiation of glutamatergic synaptic transmission. For example, olfactory discrimination learning is significantly affected by aging in mice and this may be due, in part, to diminished synaptic plasticity in piriform cortex. In the present study, we tested for alterations in electrophysiological properties and synaptic transmission in this simple cortical network. Whole-cell recordings were made from principal neurons in slices of anterior piriform cortex from young (3-6 months old) and old (24-28 months) C57BI/6 mice. Miniature excitatory postsynaptic currents (mEPSCs) mediated by AMPA receptors were collected from cells in presence of tetrodotoxin (TTX) and held at $-80 \mathrm{mV}$ in voltage-clamp. Amplitudes of mEPSCs were significantly reduced in aged mice, suggesting that synaptic AMPA receptor expression is decreased during aging. In a second set of experiments, spontaneous excitatory postsynaptic currents (s/mEPSCs) were recorded in slices from different cohorts of young and old mice, in the absence of TTX. These currents resembled mEPSCs and were similarly reduced in amplitude in old mice. The results represent the first electrophysiological evidence for age-related declines in glutamatergic synaptic function in the mammalian olfactory system.

Keywords: piriform cortex, mEPSC, LTP, AMPA, aging, mouse, olfaction

\section{INTRODUCTION}

Changes in the nervous system with aging are profound and mysterious. The brain exhibits subtle alterations in cellular morphology, synaptic structure, gene expression patterns, and electrophysiological characteristics as it ages; less subtle, perhaps, are the sensory, motor, and cognitive declines that accompany the aging process. Understanding the relationships between neurobiological changes and functional outcomes is one of the fundamental challenges of aging neuroscience. Considerable progress has been made in correlating age-dependent changes in hippocampal circuitry to spatial learning and memory deficits in aging animals. Two general principles have emerged from studies of hippocampal long-term potentiation (LTP) in aged animals (Burke and Barnes, 2010): first, age-dependent effects on synaptic function are regionally heterogeneous. For example, synaptic density declines in the dentate gyrus, but not field CA1, of old rats. Electrophysiological studies using minimal stimulation suggest that "basal" synaptic potency, the average size of the postsynaptic response to a presynaptic release event (Stevens and Wang, 1994), declines with extreme age in CA1 but not dentate. Second, LTP induction mechanisms are typically only impaired when stimulation is close to the induction threshold; LTP expression, provided that induction conditions are suprathreshold, appears normal (Burke and Barnes, 2010).

The olfactory system has a number of advantages for neurobiological studies of sensory and cognitive functions in aging. Olfactory discrimination ability declines markedly in human aging (Doty et al., 1984; Cain and Stevens, 1989) and appears to be particularly vulnerable to age-related neurodegenerative disease
(Serby et al., 1985; Kesslak et al., 1988). Olfactory dysfunction has also been reported for aging rodents (Roman et al., 1996; Frick et al., 2000; Schoenbaum et al., 2002; Enwere et al., 2004; Prediger et al., 2005; LaSarge et al., 2007). For instance, a recent study from our laboratory found that old mice took more trials to learn two-odor discrimination problems for positive reinforcement and failed to show improvement across multiple discrimination problems when compared to young mice (Patel and Larson, 2009). However, the neurobiological bases for these deficits are largely unexplored.

The primary olfactory (piriform) cortex receives monosynaptic input from the mitral (and tufted) cells of the olfactory bulb, which themselves receive monosynaptic input from primary sensory neurons in the olfactory epithelium. Layer II pyramidal neurons of piriform cortex appear to be situated to form combinatorial representations of the different olfactory bulb glomeruli that respond to distinct molecular features of the chemicals comprising an odor (Wilson and Sullivan, 2011). Piriform neurons project monosynaptically to the lateral entorhinal cortex, providing olfactory input to the hippocampal formation, as well as to parts of the amygdalar complex and the prefrontal cortex (Shipley et al., 1995). Both the afferent synapses made by the mitral cells onto layer II pyramidal cells and the associational feedback system generated by neighboring pyramidal cells are glutamatergic and exhibit LTP (Jung et al., 1990a,b; Kanter and Haberly, 1990), possibly to strengthen representations of learned odors or to participate in odor-reward associations. The present studies were directed to test for synaptic functional changes in anterior piriform cortex (APC) of aged mice. The results provide the first 
direct evidence that aging results in decreases in synaptic currents mediated by AMPA-type glutamate receptors in a simple cortical network.

\section{MATERIALS AND METHODS ANIMALS}

$\mathrm{C} 57 \mathrm{Bl} / 6 \mathrm{~J}$ mice were bred in the Psychiatric Institute vivarium from breeding stock obtained from Jackson Laboratories (Bar Harbor, ME, USA). Mice were weaned at 21 days of age and males were separated and housed in groups of two to four per cage until sacrificed for experiments. Food and water were available ad libitum and routine veterinary visits ensured that animals were in good health prior to experimentation. Any animals that displayed physical ailments or lethargy were excluded from this study. Electrophysiological experiments were conducted on brain slices obtained from mice aged 3-6 months ("young"; $n=16$ ) or 24-28 months ("old"; $n=12$ ). All procedures were in accordance with NIH guidelines and protocols were approved by the Animal Care Committee of the University of Illinois at Chicago (UIC ACC \#09-232).

\section{ELECTROPHYSIOLOGY}

\section{In vitro slice preparation and electrophysiology}

Parasagittal slices $(300 \mu \mathrm{m})$ of APC were prepared in the usual method. Mice were decapitated and brains removed in oxygenated artificial cerebral spinal fluid (aCSF) containing (in $\mathrm{mM}$ ): $\mathrm{NaCl}$ (120), $\mathrm{KCl}$ (3.1), $\mathrm{K}_{2} \mathrm{HPO}_{4}$ (1.25), $\mathrm{NaHCO}_{3}$ (26), dextrose (5.0), L-ascorbate (2), $\mathrm{MgCl}_{2}(1.0), \mathrm{CaCl}_{2}(2.0)$ at $\sim 4^{\circ} \mathrm{C}$. The brain was then sectioned into blocks (2-3 mm thick), mounted on a cutting stage, and sliced on a vibrating cutter (Vibratome, St. Louis, MO, USA). The slices were incubated at $32^{\circ} \mathrm{C}$ for $1 \mathrm{~h}$ and then allowed to cool to room temperature $\left(\sim 25-27^{\circ} \mathrm{C}\right)$. Slices were then transferred to a submerged recording chamber and perfused with aCSF. Recordings were obtained from principal cells in layer II at room temperature, as described previously (Gocel and Larson, 2012). Patch electrodes (1.8-3 M $\Omega$ ) contained (in $\mathrm{mM}$ ): cesium methanesulfonate (145), $\mathrm{MgCl}_{2}$ (1), HEPES (10), BAPTA (1.1), MgATP (5), and phosphocreatine (20) adjusted to $\mathrm{pH} 7.2$ with $\mathrm{CsOH}, 290 \mathrm{mOsm}$. Cells were visualized with differential interference contrast (DIC) optics on a Nikon Eclipse E600FN "PhysioStation" (Nikon, Melville, NY, USA). Twisted bipolar electrodes (custom made) with a tip diameter $\sim 50 \mu \mathrm{m}$ were positioned in layer Ia and Ib 150-200 $\mu \mathrm{m}$ rostral from the recorded cell. Stimulation $(0.1 \mathrm{~ms}$ pulses $1-200 \mu \mathrm{A})$ in these layers activate afferent lateral olfactory tract (LOT) and intrinsic association (ASSN) fibers synapsing onto principal cells in layer II. Responses at ASSN synapses display paired-pulse depression whereas stimulation of afferent LOT fibers in layer Ia exhibit facilitation (Bower and Haberly, 1986). Therefore, stimulation of ASSN fibers in layer Ib was confirmed after obtaining whole-cell recording by non-facilitating responses to paired-pulse stimulation at a $200 \mathrm{~ms}$ inter-pulse interval (IPI). Evoked excitatory postsynaptic currents (EPSCs), miniature EPSCs (mEPSCs) and spontaneous EPSCs (s/mEPSCs) were recorded with an Axopatch-1D amplifier and pClamp software (Molecular Devices, Sunnyvale, CA, USA), filtered at $1 \mathrm{kHz}$, digitized at $10 \mathrm{kHz}$, and stored on the computer hard drive. Cells were immediately rejected if series resistance exceeded $15 \mathrm{M} \Omega$ upon obtaining whole-cell recording configuration. Series and whole-cell capacitance compensation and junction potential correction were not used.

\section{PHARMACOLOGY}

All drugs and chemicals were applied via the perfusate by a solenoid-controlled gravity-feed system (ValveLink 8, AutoMate Scientific, Inc., Berkeley, CA, USA). The rate of flow of all drug perfusates was equilibrated to $2 \mathrm{~mL} / \mathrm{min}$ prior to the inception of experimentation. $\mathrm{GABA}_{\mathrm{A}}$ mediated transmission was blocked by $25 \mu \mathrm{M} 1(\mathrm{~S}), 9(\mathrm{R})-(-)$-bicuculline methiodide (BMI) in all experiments in order to isolate postsynaptic excitatory currents. The NMDA receptor antagonist, 3-[(R)-2-carboxypiperazin-4yl]-prop-2-enyl-1-phosphonic acid (CPP, $20 \mu \mathrm{M})$ ) was used to isolate AMPA receptor-mediated currents. $1 \mu \mathrm{M}$ tetrodotoxin (TTX) was added to the perfusate in order to eliminate spontaneous action potential-dependent events. Some experiments used 6-cyano-7-nitroquinoxaline-2,3-dione (CNQX) to block AMPA receptors $(20 \mu \mathrm{M})$. All drugs were taken from stock solutions dissolved in $\mathrm{H}_{2} \mathrm{O}$ and diluted in aCSF as needed.

\section{EVOKED SYNAPTIC CURRENTS}

In experiments using synaptic stimulation under voltage-clamp, the following stimulation protocol was used: each trial began with a baseline recording period of $300 \mathrm{~ms}$, followed by paired-pulse stimulation of the LOT (50 ms IPI), a one-second delay, and paired-pulse stimulation of the ASSN fibers (50 ms IPI). Stimulation current levels were set to yield a reliable response with the least amount of stimulation in order to avoid polysynaptic activity or synaptic population crosstalk. Stimulation intensities were the following: LOT: $3-6$ months, $40.61 \pm 12.12 \mu \mathrm{A}$; $24-28$ months, $120.00 \pm 47.97 \mu \mathrm{A}$ and ASSN: 3-6 months, $26.17 \pm 3.02 \mu \mathrm{A}$, $24-28$ months, $60.89 \pm 11.17 \mu \mathrm{A}$. Any recordings demonstrating polysynaptic activity were excluded from analysis. Measurements of averaged (50-100 trials) current attributes were performed in Clampfit.

\section{mEPSC AND s/mEPSC ANALYSIS}

For analysis of mEPSCs, slices were perfused with TTX $(1 \mu \mathrm{M})$ until whole-cell currents evoked by LOT and ASSN fiber stimulation were abolished. Cells were maintained at a holding potential of $-80 \mathrm{mV}$ throughout recordings and bicuculline and CPP were used to prevent activation of $\mathrm{GABA}_{A}$ and NMDA receptors, respectively. Spontaneous synaptic currents were recorded for $200 \mathrm{~s}$ of continuous recording from every cell. mEPSCs were identified as follows: A single $50 \mathrm{~ms}$ variable amplitude template was constructed (Clements and Bekkers, 1997) from $>20$ visuallyidentified events in a randomly-selected cell and served as a search criterion for collecting and aligning mEPSCs and s/mEPSCs for all cells. Cells were excluded from analysis if the baseline drifted more than $50 \mathrm{pA}$ or if access resistance changed more than $20 \%$ throughout the $200 \mathrm{~s}$ of continuous recording. All compound events were excluded from analysis. Measurements of the current waveforms (kinetics) were obtained from an average of all events $(>100)$ that met analysis criteria in each cell. Decay time constants were fit to averaged mEPSCs with the standard exponential equation 
$I(t)=I \times \exp (-t / \tau)$, where $I$ is the peak amplitude and $\tau$ is a the decay time constant.

Spontaneous EPSCs (s/mEPSCs) were recorded and quantified as for mEPSCs, except that TTX was not used.

\section{HISTOLOGY}

Some cells used for electrophysiology were also filled with a $4 \%$ Lucifer yellow solution passively during the recordings. Brain sections were then immediately fixed in $4 \%$ paraformaldehyde overnight, whole mounted on glass slides and coverslipped. Additional physiological slices fixed in $4 \%$ paraformaldehyde were cryoprotected in $30 \%$ sucrose in PBS. These slices were then resectioned at $30 \mu \mathrm{m}$, processed, and stained with $0.1 \%$ cresyl violet. Filled cells were visualized under a fluorescein isothiocyanate (FITC) filter and stained slices were visualized under bright field illumination on an Axioskop 2 microscope. Images were acquired through Axiovision software (Zeiss, Thornwood, NY, USA) and edited in GNU image manipulation program (GIMP, open source).

\section{STATISTICS}

All data are based on cells as individual sample units and are presented as means \pm SEM. Statistical differences between two groups were evaluated using Student's unpaired $t$-test. Analysis of variance was used for comparisons involving more than two groups.

\section{RESULTS}

A subset of the cells chosen for electrophysiological study were filled with Lucifer yellow to confirm that they were layer II pyramidal cells (Figure 1). Filled cells from mice at all ages showed multiple, spiny apical dendrites which projected toward the pial surface. Other slices stained with cresyl violet were examined for cytoarchitecture. There were no obvious differences in soma morphology, cortical lamination, or cell density of APC of 3-6 months old and 24-28 months old mice.

\section{AMPA RECEPTOR-MEDIATED mEPSCs ARE SMALLER IN THE AGED MOUSE}

As described previously (Gocel and Larson, 2012), superficial pyramidal (SP) neurons held at $-80 \mathrm{mV}$ under voltage clamp in the presence of BMI, CPP, and TTX showed spontaneous inward currents with the characteristics of mEPSCs, in slices from both young and old mice (Figure 2A). These events were abolished by perfusion with $\mathrm{CNQX}$, confirming that they were mediated by AMPA receptors (data not shown). Synaptic events were collected from continuous $200 \mathrm{~s}$ recording epochs, aligned, averaged, and analyzed. Amplitude distributions were positively skewed in both young (Figure 2B) and old mice (Figure 2C). The mean amplitudes of mEPSCs recorded in slices from old mice were significantly smaller than those from young mice (Figure 2D). Since the amplitude distributions were skewed, the median mEPSC amplitude was also calculated for each cell and compared between age groups. These measures were also significantly smaller in the aged mice (young: $12.31 \pm 0.51 \mathrm{pA}$; old: $9.95 \pm 0.53 \mathrm{pA}$; $p<0.01)$. The average frequency of detected mEPSCs did not significantly differ between age groups (Figure 2E). Cumulative

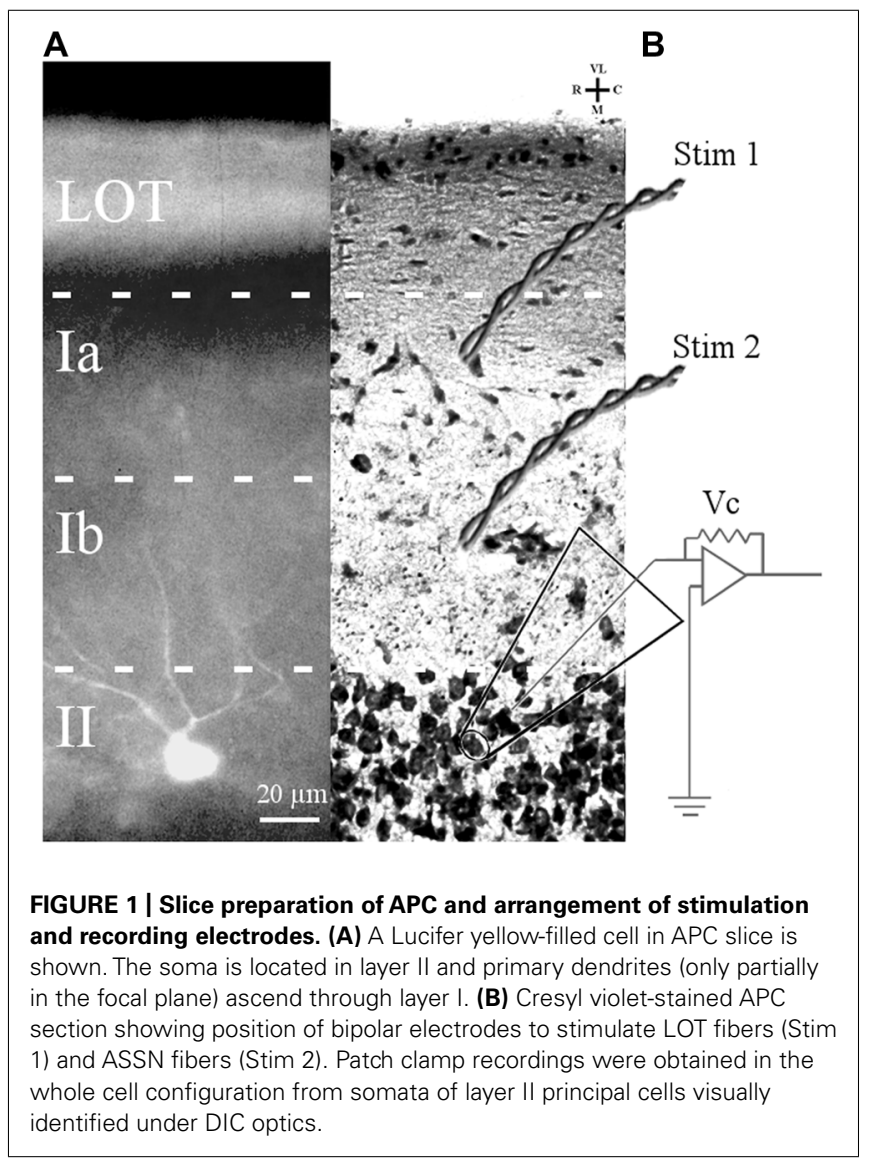

amplitude distributions (Figure 2F) also illustrate the shift in amplitude toward smaller mEPSCs in the neurons from old mice. Possible age-related changes in the kinetics of AMPA receptors mediating mEPSCs were calculated by fitting a single exponential function to the decay phase of averaged mEPSCs in each cell. The decay time constants tended to be longer in cells from old mice, although this difference only approached statistical significance (young: $4.22 \pm 0.16 \mathrm{~ms}, n=24$; old: $4.72 \pm 0.18 \mathrm{~ms}, n=14$; $\left.t_{36}=1.95, p=0.06\right)$.

\section{PAIRED-PULSE RESPONSES ARE UNAFFECTED BY AGING}

The vast majority of glutamatergic synapses on SP neurons in APC are generated by either afferents from the olfactory bulb (LOT), terminating in the outer molecular layer (Ia) or the intrinsic associational (ASSN) system generated by the SP neurons themselves and terminating in the inner molecular layer (Ib). To test whether or not changes in the potency of individual synapses (mEPSCs) with aging were accompanied by presynaptic changes in release characteristics at either or both of these systems, paired-pulse stimulation (50 ms IPI) was applied to each pathway while recording from cells held at $-80 \mathrm{mV}$ in slices from young and old mice. Cells were only included in analysis if responses were present from both synaptic pathways. All traces collected for a given cell which met criteria were averaged and the percent potentiation or depression of the second response was calculated relative to that of the first response (Figure 3). The robust facilitation of responses to LOT stimulation was not significantly altered by 
A
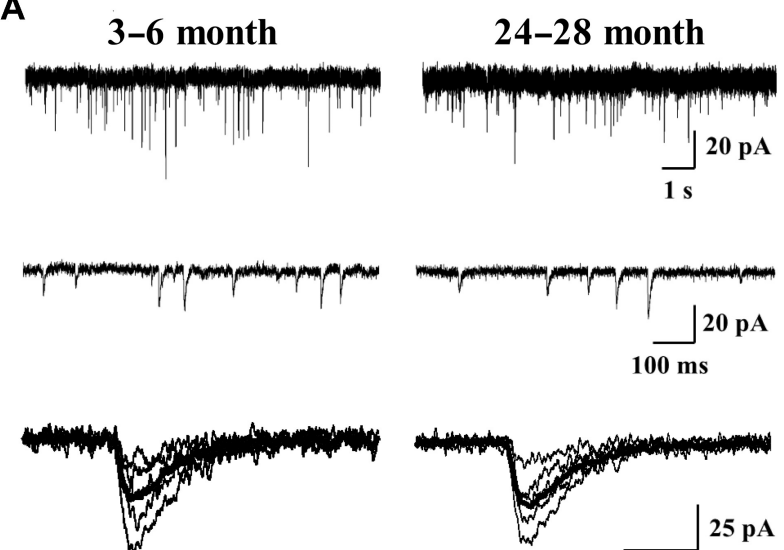

B

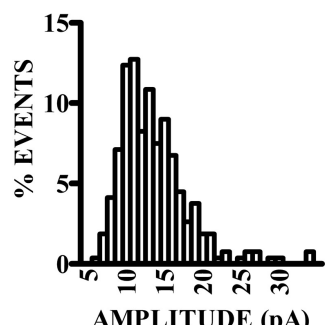

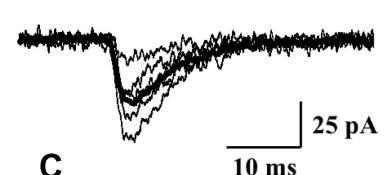

C

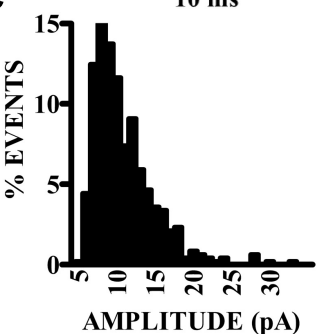

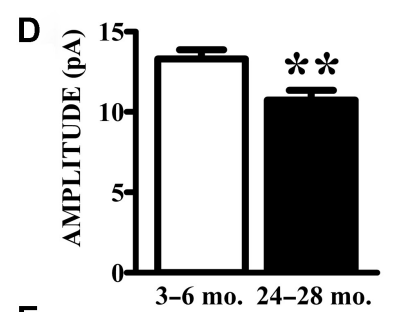

E

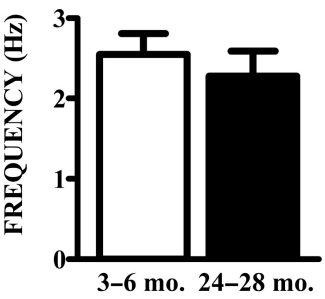

$\mathbf{F}$

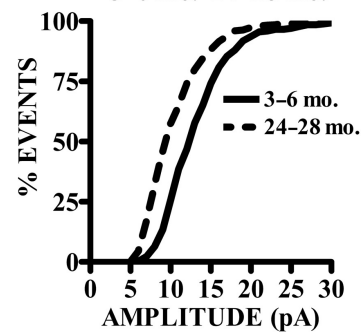

FIGURE 2 | AMPA receptor-mediated currents at single synapses are reduced in aged mice. (A) mEPSCs were collected in the presence of TTX. Top raw traces were extracted from $200 \mathrm{~s}$ recording epochs from which spontaneous currents were collected. Middle traces are expanded sections of the top traces; a template algorithm was used to search for individual currents. Bottom traces are selected individual mEPSCs aligned according to onset of the current. (B,C) All currents collected during the $200 \mathrm{~s}$ epochs were binned according to amplitude. As demonstrated by these representative histograms, AMPA mEPSC amplitude histograms in old (24-28 months) animals (C) demonstrated a leftward shift in distribution as compared to young (3-6 months) animals (B). (D) Mean amplitudes (shown) of AMPA mEPSCs were significantly decreased in old relative to young mice $\left(t_{36}=2.87, p<0.01\right.$ ). Comparison of both age groups according to the median amplitude (not shown) also demonstrated a reduction. (E) The frequency of mEPSCs was comparable between age groups. Frequency was determined by counting the events that occurred during the entire 200-s recording epochs. (F) Cumulative distributions illustrate the shift in the mEPSC amplitudes. age. ASSN responses showed neither facilitation nor depression at the interval tested; normalized responses were also unaffected by age.

\section{SPONTANEOUS SYNAPTIC CURRENTS (s/mEPSCs) ARE REDUCED IN THE AGED MOUSE}

Spontaneous currents in the absence of stimulation were obtained from the same cells in which evoked paired-pulse responses were obtained. Experiments were performed in the absence of TTX in order to obtain evoked responses; therefore, the spontaneous currents collected are presumed to be a mixture of action potential-dependent (sEPSCs) and independent (mEPSCs) events. The manner of analysis was identical to the method of analyzing mEPSC data. Aged animals exhibited a significant reduction in mean (Figure 4) and median (young: $12.78 \pm 0.53 \mathrm{pA}$; old: $10.69 \pm 0.41 \mathrm{pA} ; p<0.01) \mathrm{s} / \mathrm{mEPSC}$ amplitude. The similar size of mEPSCs recorded in the presence of TTX (Figure 2) and s/mEPSCs recorded in the absence of TTX (Figure 4) suggests either (1) that action potential-dependent and -independent release events evoke similar postsynaptic responses or (2) that the action potential-dependent (TTX-sensitive) events are a small fraction of spontaneous release events in these cells. Frequency distributions of s/mEPSC amplitudes also did not reveal any obvious differences with those of mEPSCs. In any case, it bears noting that the s/mEPSC (Figure 4) and mEPSC (Figure 2) recordings were made from completely different sets of young and old animals.

\section{DISCUSSION}

There is compelling evidence that olfaction-mediated sensory and cognitive functions decline with aging in humans (Doty et al., 1984; Cain and Stevens, 1989; Wysocki and Gilbert, 1989; Larsson et al., 2000, 2006; Gilbert et al., 2008) and experimental animals (Roman et al., 1996; Frick et al., 2000; Enwere et al., 2004; Prediger et al., 2005; LaSarge et al., 2007; Dardou et al., 2008; Luu et al., 2008; Patel and Larson, 2009). The piriform cortex occupies a strategic position in the neural processing of odors: (i) it is the largest target of efferents from the olfactory bulb (Neville and Haberly, 2004); (ii) its internal wiring suggests a combinatorial mechanism for synthetic integration of odor percepts from multiple chemical constituents that activate distinct odorant receptor proteins and corresponding glomeruli in the olfactory bulb (Haberly, 2001; Franks and Isaacson, 2006; Stettler and Axel, 2009; Wilson and Sullivan, 2011); (iii) odor discrimination and olfactory learning are disrupted by piriform lesions (Staubli et al., 1987); (iv) olfactory training modifies synaptic structure and function in 


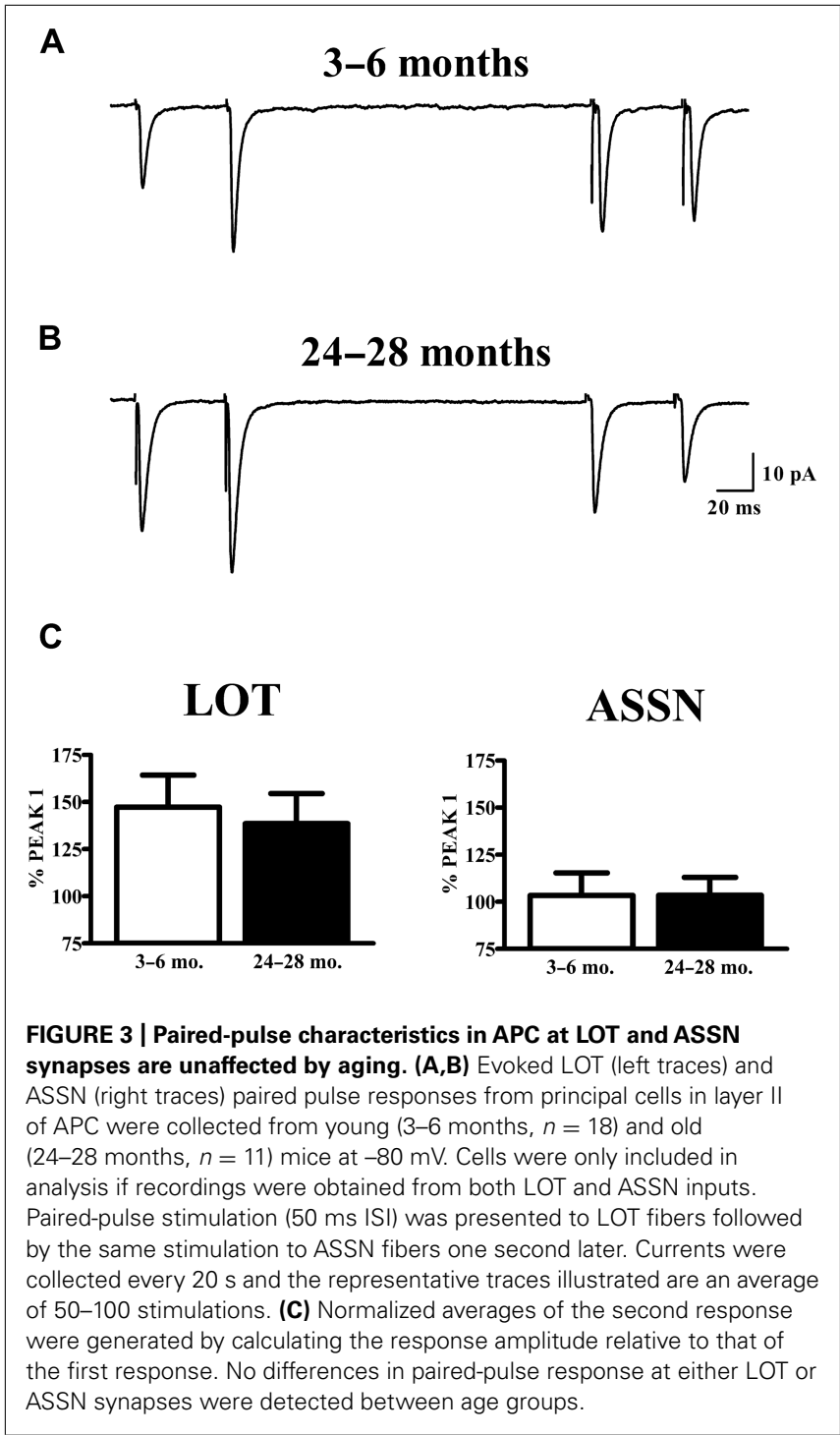

piriform cortex (Barkai and Saar, 2001); and (v) it is the primary pathway by which olfactory information reaches the hippocampus, amygdala, and prefrontal cortex (Shipley et al., 1995). However, this structure has received very little attention in neurobiological studies of aging. The present study represents an initial step in a comprehensive analysis of the brain substrate for olfactory dysfunction in aging.

We recorded from principal neurons in primary olfactory cortex from young adult and aged mice. The main finding of the experiments described here is a decrease in the amplitude of synaptic currents mediated by AMPA receptors on these cells in aged mice. TTX-resistant spontaneous synaptic currents (mEPSCs) are thought to be evoked by stochastic release of single glutamate quanta at individual synapses. Assuming that synaptic vesicles are the physical basis for quantal release, there are two main ways to alter quantal size: a change in glutamate loading of vesicles or a change in postsynaptic receptors in the synaptic zone. There is little precedent for changes in vesicle loading but considerable evidence that postsynaptic AMPA receptor numbers can be

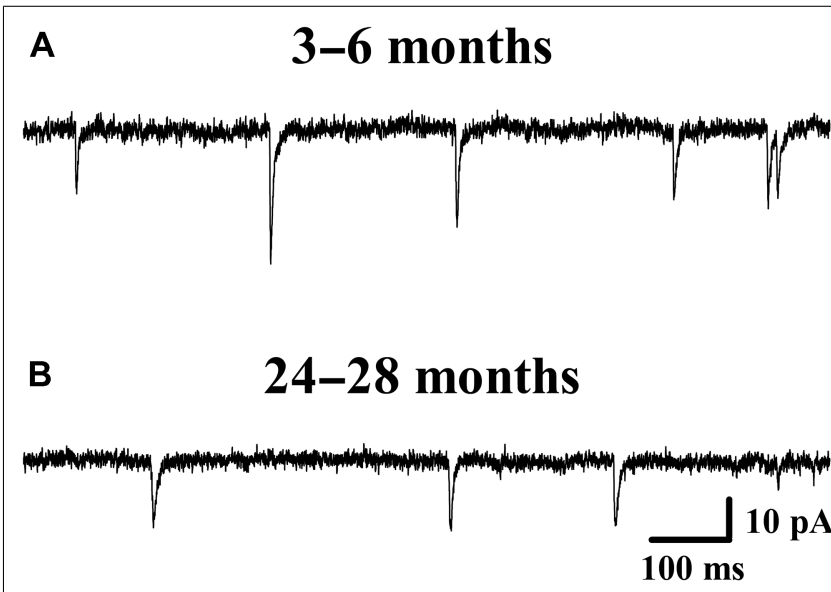

C s/mEPSC

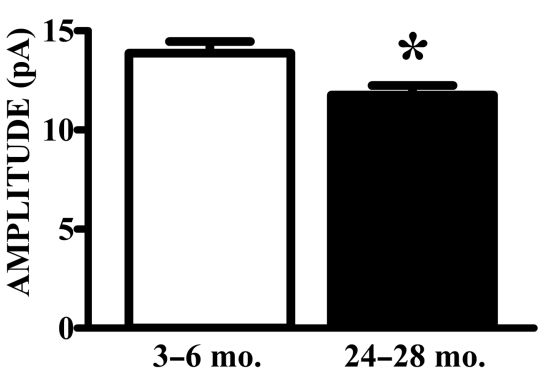

FIGURE 4 | AMPA s/mEPSC amplitudes are reduced in APC of old mice. $(\mathbf{A}, \mathbf{B})$ Raw traces illustrated include events collected during recording periods where no stimulation was presented in the same cells shown in Figure 3. Spontaneous currents (s/mEPSCs) in these recordings are presumed to emanate from action potential-mediated and -independent events since TTX was not present in the perfusate. (C) The mean amplitude of $\mathrm{s} / \mathrm{mEPSC} \mathrm{s}$ was calculated and averaged across cells. Events collected from aged (24-28 months, $n=11)$ mice demonstrated a decrease in amplitude compared to those from young ( $3-6$ months, $n=18$ ) mice $\left(t_{27}=2.48, p<0.05\right)$.

altered in an experience-dependent manner (Lynch and Baudry, 1984; Bredt and Nicoll, 2003) or in certain disease models (Li et al., 2002). Therefore the most parsimonious interpretation of a decrease in mEPSC size is a reduction in the number of functional AMPA receptors activated by synaptic glutamate release in the aged mice. In theory, a postsynaptic mechanism could be confirmed or ruled out by measuring NMDA receptor-mediated mEPSCs; however, this was impractical due to the voltage-dependence and slow kinetics of NMDA receptor-mediated currents. On the other hand, there are numerous reports of decreases in AMPA receptor expression, measured by mRNA or protein expression or ligand binding, in various brain regions of aged rodents (Bahr et al., 1992; Magnusson and Cotman, 1993; Nicoletti et al., 1995; Nicolle et al., 1996; Magnusson, 1998; Wenk and Barnes, 2000; Majdi et al., 2009).

It is important to note that spontaneous EPSCs (sEPSCs) were also recorded from APC cells in slices from completely 
independent cohorts of young and old mice, in the absence of TTX. The amplitude distributions of these events were almost identical to the events (mEPSCs) recorded in slices exposed to TTX. This suggests that the sEPSCs and mEPSCs are the same events; the lack of TTX sensitivity may be attributed to the high resting membrane potentials and low spontaneous firing of piriform pyramidal cells in vitro (Scholfield, 1978; Tseng and Haberly, 1988; Suzuki and Bekkers, 2006). In any case, the smaller amplitude of spontaneously-occurring synaptic AMPA currents in cells from old mice was replicated for both mEPSCs and "sEPSCs," in different cohorts of mice.

The frequency of mEPSCs was not altered in the aged mice, suggesting that either (i) no change in the number of synapses contributing to these synapses with aging or (ii) that any such changes are accompanied by compensatory changes in spontaneous release probability. The synaptic origin of the mEPSCs could not be determined in these experiments. However, it is worth noting that the paired-pulse experiments did not reveal any differences that would be indicative of changes in release probability in either the LOT or ASSN pathways in young versus old mice. It is also worth noting that paired-pulse ratios may not be very sensitive measures of release kinetics.

In toto, the results of the present study point to the conclusion that aging results in a loss of functional AMPA receptors at synapses on layer II pyramidal cells in piriform cortex. These losses may occur at LOT synapses, ASSN synapses, or both. Further studies will be necessary to establish whether these AMPA receptor losses are due to alterations in receptor subunit

\section{REFERENCES}

Bahr, B. A., Godshall, A. C., Hall, R. A., and Lynch, G. (1992). Mouse telencephalon exhibits an age-related decrease in glutamate (AMPA) receptors but no change in nerve terminal markers. Brain Res. 589, 320-326. doi: 10.1016/0006-8993(92)91293-N

Barkai, E., and Saar, D. (2001). Cellular correlates of olfactory learning in the rat piriform cortex. Rev. Neurosci. 12, 111-120. doi: 10.1515/REVNEURO. 2001.12.2.111

Barnes, C. A., and McNaughton, B. L. (1980). Physiological compensation for loss of afferent synapses in rat hippocampal granule cells during senescence. J. Physiol. 309, 473-485.

Barnes, C. A., Rao, G., Foster, T. C., and McNaughton, B. L. (1992). Region-specific age effects on AMPA sensitivity: electrophysiological evidence for loss of synaptic contacts in hippocampal field CA1. Hippocampus 2, 457-468. doi: 10.1002/ hipo.450020413

Bower, J. M., and Haberly, L. B. (1986). Facilitating and nonfacilitating synapses on pyramidal cells: a correlation between physiology and morphology. Proc. Natl. Acad. Sci. U.S.A. 83, 1115-1119. doi: 10.1073/ pnas.83.4.1115
Bredt, D. S., and Nicoll, R. A. (2003). AMPA receptor trafficking at excitatory synapses. Neuron 40, 361-379. doi: 10.1016/S08966273(03)00640-8

Burke, S. N., and Barnes, C. A. (2010) Senescent synapses and hippocampal circuit dynamics. Trends Neurosci. 33, 153-161. doi: 10.1016/j.tins. 2009.12.003

Cain, W. S., and Stevens, J. C. (1989). Uniformity of olfactory loss in aging. Ann. N. Y. Acad. Sci. 561, 29-38. doi: 10.1111/j.1749-6632. 1989.tb20967.x

Clements, J. D., and Bekkers, J. M. (1997). Detection of spontaneous synaptic events with an optimally scaled template. Biophys. J. 73, 220-229. doi: 10.1016/S00063495(97)78062-7

Dardou, D., Datiche, F., and Cattarelli, M. (2008). Memory is differently impaired during aging according to the learning tasks in the rat. Behav. Brain Res. 194, 193-200. doi: 10.1016/j.bbr.2008.07.007

Doty, R. L., Shaman, P., Applebaum, S. L., Giberson, R., Siksorski, L., and Rosenberg, L. (1984). Smell identification ability: changes with age. Science 226, 1441-1443. doi: 10.1126/ science. 6505700

transcription, translation, trafficking, post-translational modification, or receptor assembly, as well as whether or not synaptic NMDA receptors are similarly effecting by aging. The decrease in synaptic potency with aging observed in the present study is in contrast to studies using minimal stimulation in rat hippocampal formation where the results suggest that dentate synapses increase in potency (larger unitary EPSPs) while CA1 synapses remain unchanged in old age (Barnes and McNaughton, 1980; Foster et al., 1991; Barnes et al., 1992).

A loss of synaptic AMPA receptors would not be expected to be without effect on LTP in the APC. Although the effects of aging on LTP have not been studied in piriform cortex, activation of more synapses with fewer AMPA receptors would be needed to trigger LTP in aged mice, in order to overcome the voltage-dependent block of NMDA receptors during high frequency stimulation. A disturbance of LTP might not be evident with supramaximal stimulation paradigms but may appear with near threshold stimulation, as observed in hippocampal field CA1. In this scenario, enhancement of AMPA receptor function might compensate for loss of synaptic AMPA receptors. Drugs that act in this way are known to facilitate olfactory learning in young animals (Larson et al., 1995) and may alleviate some of the learning deficits shown by aged mice.

\section{ACKNOWLEDGMENTS}

The research was supported by grants from the National Institutes of Health (DC5793) and the U.S. Army Medical Research and Materiel Command (\#10917352).

Enwere, E., Shingo, T., Gregg C., Fujikawa, H., Ohta, S., and Weiss, S. (2004). Aging results in reduced epidermal growth factor receptor signaling, diminished olfactory neurogenesis, and deficits in fine olfactory discrimination. J. Neurosci. 24, 8354-8365. doi: 10.1523/ JNEUROSCI.2751-04.2004

Foster, T. C., Barnes, C. A., Rao, G., and McNaughton, B. L. (1991). Increase in perforant path quantal size in aged F-344 rats. Neurobiol. Aging 12, 441-448. doi: 10.1016/01974580(91)90071-Q

Franks, K. M., and Isaacson, J. S. (2006). Strong single-fiber sensory inputs to olfactory cortex: implications for olfactory coding. Neuron 49, 357-363. doi: 10.1016/j.neuron. 2005.12.026

Frick, K. M., Burlingame, L. A., Arters, J. A., and Berger-Sweeney, J. (2000). Reference memory, anxiety and estrous cyclicity in C57BL/6NIA mice are affected by age and sex. Neuroscience 95, 293-307. doi: 10.1016/S0306-4522(99)00418-2

Gilbert, P. E., Pirogovsky, E., Ferdon, S., Brushfield, A. M., and Murphy, C. (2008). Differential effects of normal aging on memory for odorplace and object-place associations.
Exp. Aging Res. 34, 437-452. doi: 10.1080/03610730802271914

Gocel, J., and Larson, J. (2012). Synaptic NMDA receptor-mediated currents in anterior piriform cortex are reduced in the adult fragile $\mathrm{X}$ mouse. Neuroscience 221, 170-181. doi: 10.1016/j.neuroscience.2012.06.052

Haberly, L. B. (2001). Paralleldistributed processing in olfactory cortex: new insights from morphological and physiological analysis of neuronal circuitry. Chem. Senses 26, 551-576. doi: 10.1093/chemse/ 26.5.551

Jung, M. W., Larson, J., and Lynch, G. (1990a). Long-term potentiation of monosynaptic EPSPs in rat piriform cortex in vitro. Synapse 6, 279-283. doi: 10.1002/syn.890060307

Jung, M. W., Larson, J., and Lynch, G. (1990b). Role of NMDA and non-NMDA receptors in synaptic transmission in rat piriform cortex. Exp. Brain Res. 82, 451-455. doi: 10.1007/BF00231264

Kanter, E. D., and Haberly, L. B. (1990). NMDA-dependent induction of long-term potentiation in afferent and association fiber systems of piriform cortex in vitro. Brain Res. 525, 175-179. doi: 10.1016/00068993(90)91337-G 
Kesslak, J. P., Cotman, C. W., Chui, H. C., Van den Noort, S., Fang, H., Pfeffer, R., et al. (1988). Olfactory tests as possible probes for detecting and monitoring Alzheimer's disease. Neurobiol. Aging 9, 399-403. doi: 10.1016/S0197-4580 (88)80087-3

Larson, J., Lieu, T., Petchpradub, V., LeDuc, B., Ngo, H., Rogers, G. A., et al. (1995). Facilitation of olfactory learning by a modulator of AMPA receptors. J. Neurosci. 15, 8023-8030.

Larsson, M., Finkel, D., and Pedersen, N. L. (2000). Odor identification: influences of age, gender, cognition, and personality. J. Gerontol. B Psychol. Sci. Soc. Sci. 55, 304-310. doi: 10.1093/geronb/55.5.P304

Larsson, M., Oberg, C., and Backman, L. (2006). Recollective experience in odor recognition: influences of adult age and familiarity. Psychol. Res. 70, 68-75. doi: 10.1007/s00426004-0190-9

LaSarge, C. L., Montgomery, K. S., Tucker, C., Slaton, G. S., Griffith, W. H., Setlow, B., et al. (2007). Deficits across multiple cognitive domains in a subset of aged Fischer 344 rats. Neurobiol. Aging 28, 928-936. doi: 10.1016/j.neurobiolaging.2006. 04.010

Li, J., Pelletier, M. R., Perez Velazquez, J. L., and Carlen, P. L. (2002). Reduced cortical synaptic plasticity and GluR1 expression associated with fragile $x$ mental retardation protein deficiency. Mol. Cell. Neurosci. 19, 138-151. doi: 10.1006/ mcne.2001.1085

Luu, T. T., Pirogovsky, E., and Gilbert, P. E. (2008). Age-related changes in contextual associative learning. Neurobiol. Learn. Mem. 89, 81-85. doi: 10.1016/j.nlm.2007. 09.006

Lynch, G., and Baudry, M. (1984). The biochemistry of memory: a new and specific hypothesis. Science $224,1057-1063$. doi: 10.1126/science. 6144182
Magnusson, K. R. (1998). Aging of glutamate receptors: correlations between binding and spatial memory performance in mice. Mech. Ageing Dev. 104, 227248. doi: 10.1016/S0047-6374(98) 00076-1

Magnusson, K. R., and Cotman, C. W. (1993). Age-related changes in excitatory amino acid receptors in two mouse strains. Neurobiol. Aging 14, 197-206. doi: 10.1016/01974580(93)90001-R

Majdi, M., Ribeiro-da-Silva, A., and Cuello, A. C. (2009). Variations in excitatory and inhibitory postsynaptic protein content in rat cerebral cortex with respect to aging and cognitive status. Neuroscience 159, 896907. doi: 10.1016/j.neuroscience. 2008.11.034

Neville, K. R., and Haberly, L. B. (2004). "Olfactory cortex," in The Synaptic Organization of the Brain, Vol. 5, ed. G. M. Shepherd (New York: Oxford University Press), 415-454. doi: 10.1093/acprof:oso/ 9780195159561.003 .0010

Nicoletti, V. G., Condorelli, D. F., Dell'Albani, P., Ragusa, N., and Giuffrida Stella, A. M. (1995). AMPAselective glutamate receptor subunits in the rat hippocampus during aging. J. Neurosci. Res. 40, 220-224. doi: 10.1002/jnr.490400210

Nicolle, M. M., Bizon, J. L., and Gallagher, M. (1996). In vitro autoradiography of ionotropic glutamate receptors in hippocampus and striatum of aged Long-Evans rats: relationship to spatial learning. Neuroscience 74, 741-756. doi: 10.1016/ 0306-4522(96)00147-9

Patel, R. C., and Larson, J. (2009) Impaired olfactory discrimination learning and decreased olfactory sensitivity in aged $\mathrm{C} 57 \mathrm{Bl} / 6$ mice. Neurobiol. Aging 30, 829837. doi: 10.1016/j.neurobiolaging. 2007.08.007

Prediger, R. D., Batista, L. C., and Takahashi, R. N. (2005). Caf feine reverses age-related deficits in olfactory discrimination and social recognition memory in rats. Involvement of adenosine $\mathrm{Al}$ and A2A receptors. Neurobiol. Aging 26, 957-964. doi: 10.1016/j.neurobiolaging.2004.08.012

Roman, F. S., Alescio-Lautier, B., and Soumireu-Mourat, B. (1996). Agerelated learning and memory deficits in odor-reward association in rats. Neurobiol. Aging 17, 31-40. doi: 10.1016/0197-4580(95)02030-6

Schoenbaum, G., Nugent, S., Saddoris, M. P., and Gallagher, M. (2002). Teaching old rats new tricks: age-related impairments in olfactory reversal learning. Neurobiol. Aging 23, 555-564. doi: 10.1016/S01974580(01)00343-8

Scholfield, C. N. (1978). Electrical properties of neurones in the olfactory cortex slice in vitro. J. Physiol. 275, 535-546.

Serby, M., Corwin, J., Conrad, P., and Rotrosen, J. (1985). Olfactory dysfunction in Alzheimer's disease and Parkinson's disease. Am. J. Psychiatry 142, 781-782. doi: 10.1038/nrneurol.2012.80

Shipley, M. T., McLean, J. H., and Ennis, M. (1995). “Olfactory system," in The Rat Nervous System, Vol. 2, ed. G. Paxinos (San Diego: Academic Press), 899-926.

Staubli, U., Schottler, F., and NejatBina, D. (1987). Role of dorsomedial thalamic nucleus and piriform cortex in processing olfactory information. Behav. Brain Res. 25, 117 129. doi: 10.1016/0166-4328(87) 90005-2

Stettler, D. D., and Axel, R. (2009). Representations of odor in the piriform cortex. Neuron 63, 854-864. doi: 10.1016/j.neuron.2009.09.005

Stevens, C. F., and Wang, Y. (1994). Changes in reliability of synaptic function as a mechanism for plasticity. Nature 371, 704-707. doi: 10.1038/371704a0

Suzuki, N., and Bekkers, J. M. (2006). Neural coding by two classes of principal cells in the mouse piriform cortex. J. Neurosci. 26, 11938-11947. doi: 10.1523/ JNEUROSCI.3473-06.2006

Tseng, G. F., and Haberly, L. B. (1988). Characterization of synaptically mediated fast and slow inhibitory processes in piriform cortex in an in vitro slice preparation. J. Neurophysiol. 59, 13521376.

Wenk, G. L., and Barnes, C. A. (2000). Regional changes in the hippocampal density of AMPA and NMDA receptors across the lifespan of the rat. Brain Res. 885, 1-5. doi: 10.1016/S0006-8993(00)02792-X

Wilson, D. A., and Sullivan, R. M. (2011). Cortical processing of odor objects. Neuron 72, 506-519. doi: 10.1016/j.neuron.2011.10.027

Wysocki, C. J., and Gilbert, A. N. (1989). National Geographic Smell Survey. Effects of age are heterogenous. Ann. N. Y. Acad. Sci. 561, $12-$ 28. doi: 10.1111/j.1749-6632.1989. tb20966.x

Conflict of Interest Statement: The authors declare that the research was conducted in the absence of any commercial or financial relationships that could be construed as a potential conflict of interest.

Received: 06 May 2013; accepted: 17 July 2013; published online: 06 August 2013. Citation: Gocel J and Larson J (2013) Evidence for loss of synaptic AMPA receptors in anterior piriform cortex of aged mice. Front. Aging Neurosci. 5:39. doi: 10.3389/fnagi.2013.00039

Copyright: (c) 2013 Gocel and Larson. This is an open-access article distributed under the terms of the Creative Commons Attribution License (CC BY). The use, distribution or reproduction in other forums is permitted, provided the original author(s) or licensor are credited and that the original publication in this journal is cited, in accordance with accepted academic practice. No use, distribution or reproduction is permitted which does not comply with these terms. 